I. A. MACKENZIE, L. WANG, N. P. R. ONUSKA, O. F. WILLIAMS, K. BEGAM, A. M. MORAN, B. D. DUNIETZ, D. A. NICEWICZ* (UNIVERSITY OF NORTH CAROLINA AT CHAPEL HILL, USA)

Discovery and Characterization of an Acridine Radical Photoreductant

Nature 2020, 580, 76-80.

\section{Photoexcitation of an Acridine Radical Generates a Strong Organic Single-Electron Reductant}
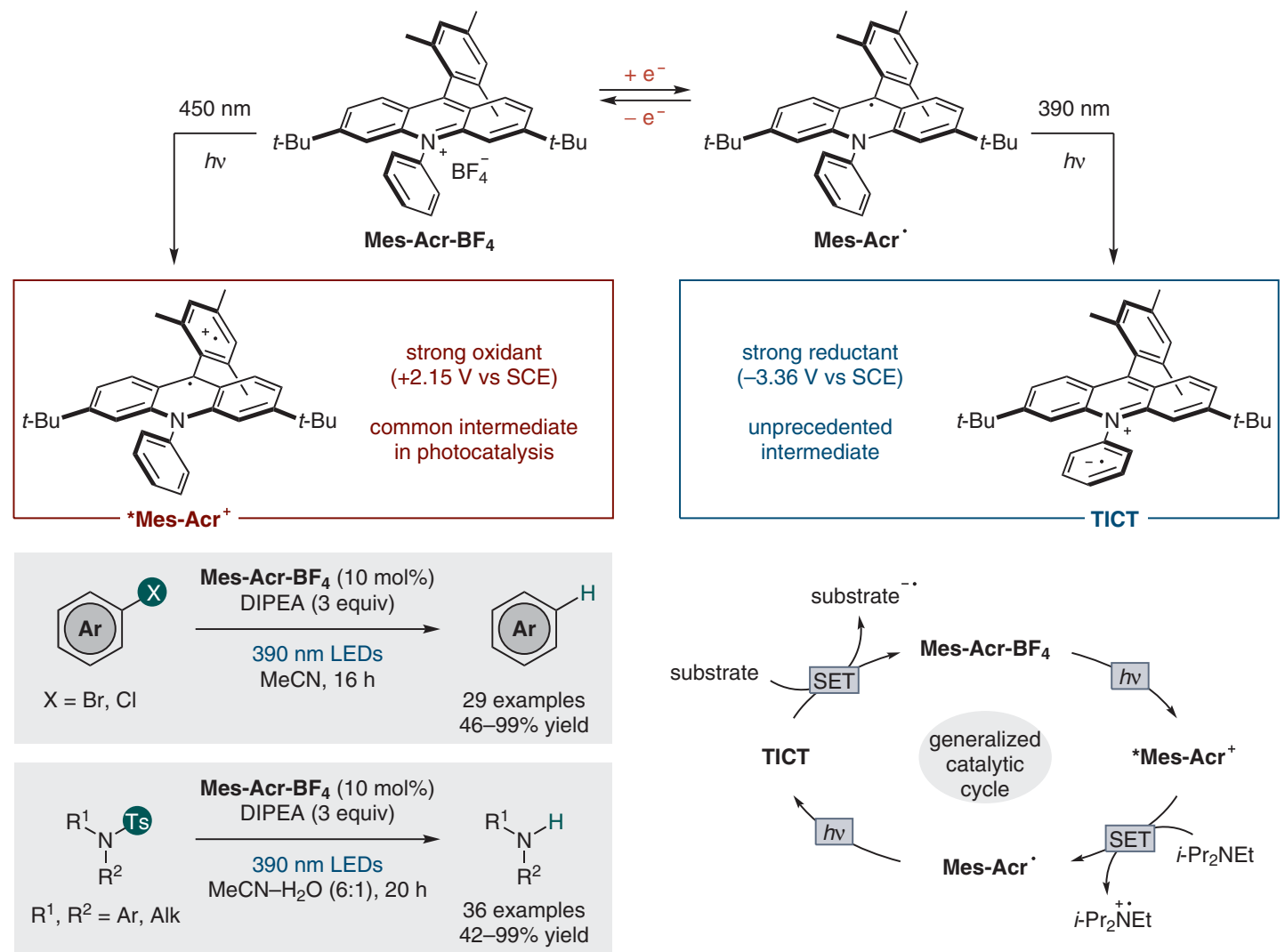

Significance: Nicewicz and co-workers report the characterization and utilization of an acridine radical derived from the common photoredox-catalyst Mes-Acr-BF 4 . The stable radical was investigated experimentally and computationally in terms of its photochemical and redox properties. Upon irradiation, two distinct excited states are populated: a doublet state $\left(D_{1}\right)$ and a twisted intramolecular charge-transfer state (TICT) in which the $N$-phenyl ring is twisted to allow charge transfer to the central acridine unit. The reduction potential of this compound was found to be as high as $-3.36 \mathrm{~V}$ (vs. saturated calomel electrode), which is comparable to that of main-group alkali metals.
Comment: The described Mes-Acr radical could be generated in situ from Mes-Acr-BF 4 through the use of $\mathrm{N}, \mathrm{N}$-diisopropylethylamine as a single-electron reductant. By applying this strategy, the photocatalytic cleavage of aromatic $\mathrm{C}-\mathrm{Cl}$ and $\mathrm{N}-\mathrm{Ts}$ bonds could be accomplished, the latter of which is usually performed by using strongly reducing alkali metals. The presented photocatalytic method is thus advantageous in terms of experimental convenience, functional-group tolerance, and atom economy. This work makes one question the inherent advantages associated with metals in organic chemistry, as well as the future limitations in reactivity for small-molecule organic catalysts.

\section{Category}

Organo- and

Biocatalysis

Key words

photocatalysis

photoreduction

visible light

acridine radical

single-electron

reduction 